\section{Complications Following Pulmonary Lobectomy: The Role of Helmet Noninvasive Ventilation}

\section{To the Editor:}

We read with great interest the paper by Barbagallo et al on prophylactic use of helmet CPAP after pulmonary lobectomy: a randomized control trial. ${ }^{1}$

Noninvasive ventilation (NIV) is a type of ventilation that does not require placement of an artificial airway. Selection of ventilation interfaces and the type of ventilator are the most important and influencing factors. Different types of interfaces have been developed over the years, but none have been clearly proven superior to another. ${ }^{2}$ Only a little attention has been paid to the type of interface used. Data on NIV in the postoperative setting are selective. The results published by Aguilo et $\mathrm{al}^{3}$ and Perrin et $\mathrm{al}^{4}$ prove the aspects of improvement in oxygenation and pulmonary function postoperatively. The paper by Barbagallo et al has enlightened the short duration of beneficial effects of NIV on oxygenation.

The objective of the study was to understand the effects of helmet NIV in patients post pulmonary lobectomy. The helmet interface, which is a recent introduction, has some important advantages in terms of improved tolerance, allows acceptable interaction with the environment, and can be used in different anatomic situations, such as edentulous and facial trauma patients. It also does not cause skin lesions. The helmet improves comfort, which permits longer periods of NIV delivery. However, because helmets are larger than facial masks, the pressure within the system during ventilation may be dissipated against the high compliance of the helmet, thus interfering with correct pressurization and ventilator function. ${ }^{5-8}$

We did not understand why the authors chose to compare helmet interface over oxygen therapy via face mask. We would like to ask the authors why they did not consider comparing helmet interface versus commonly used interfaces like facial interface. This type of comparison will provide a better insight on the beneficial effects of helmet interface in terms of tolerance and patient-ventilator synchrony. ${ }^{9}$ Age $>60$ years and COPD may have caused some amount of confounding in the study. ${ }^{10}$ The authors could have studied the number of ventilator alarms, disconnection, complications (eg, nasal breakdown), ${ }^{11}$ and total number of trouble-shootings that would provide insight on additional benefits of the helmet interface.

Overall, it is doubtful whether the beneficial effect obtained was due to CPAP or helmet interface.

\section{Ramesh Unnikrishnan MSc CRT Praveen Jacob John \\ Department of Respiratory Therapy}

Anitha Shenoy MD FRCA

Department of Anesthesiology and Department of Respiratory Therapy

Manipal College of Allied Health Sciences

Manipal, Karnataka, India

The authors have disclosed no conflicts of interest.

\section{REFERENCES}

1. Barbagallo M, Ortu A, Spadini E, Salvadori A, Ampollini L, Internullo E, et al. Prophylactic use of helmet CPAP after pulmonary lobectomy: a prospective randomized controlled study. Respir Care 2012; 57(9):1418-1424.

2. Peñuelas O, Frutos-Vivar F, Esteban A Noninvasive positive-pressure ventilation in acute respiratory failure. CMAJ 2007; 177(10):1211-1218

3. Aguilo R, Togores B, Pons S, Mateu R, Barbé F, Agusti A. Noninvasive ventilatory support after lung resectional surgery. Chest 1997;112(1):117-121.

4. Perrin C, Jullien V, Venissac N, Berthier F, Padovani B, Guillot F, et al. Prophylactic use of non-invasive ventilation in patients undergoing lung resectional surgery. Respir Med 2007;101(7):1572-1578.

5. Chiumello D, Pelosi P, Carlesso E, Severgnini P, Aspesi M, Gamberoni C, et al. Noninvasive positive-pressure ventilation delivered by helmet vs standard face mask Intensive Care Med 2003;29(10):16711679.

6. Costa R, Navalesi P, Antonelli M, Cavaliere F, Craba A, Proietti R, Conti G. Physiologic evaluation of different levels of assistance during noninvasive ventilation delivered through a helmet. Chest 2005; 128(4):2984-2990.

7. Navalesi P, Costa R, Ceriana P, Carlucci A, Prinianakis G, Antonelli M, et al. Noninvasive ventilation in chronic obstructive pulmonary disease patients: helmet versus facial mask. Intensive Care Med 2007; 33(1):74-81.
8. Moerer O, Beck J, Brander L, Costa R, Quintel M, Slutsky AS, Brunet F, et al. Subject-ventilator synchrony during neural versus pneumatically triggered noninvasive helmet ventilation. Intensive Care Med 2008;34(9):1615-1623.

9. Mathai AS. Non-invasive ventilation in the postoperative period: is there a role? Indian J Anaesth 2011;55(4):325-333.

10. Algar FJ, Alvarez A, Salvatierra A, Baamonde C, Aranda JL, López-Pujol FJ. Predicting pulmonary complications after pneumonectomy for lung cancer. Eur J Cardiothorac Surg 2003 Feb;23(2):201-208.

11. Racca F, Appendini L, Berta G, Barberis L, Vittone F, Gregoretti C, et al. Helmet ventilation for acute respiratory failure and nasal skin breakdown in neuromuscular disorders. Anesth Analg 2009;109(1):164-167.

DOI: $10.4187 /$ respcare. 02248

The authors respond to: Complications Following Pulmonary Lobectomy: The Role of Helmet Noninvasive Ventilation

We thank Unnikrishnan and colleagues for their interest in and comments regarding our recently published paper, outlining the benefit of the prophylactic use of helmet CPAP (hCPAP), in comparison to air-entrainment mask after pulmonary lobectomy. ${ }^{1}$ Our standard postoperative protocol after pulmonary lobectomy considers the use of air-entrainment mask with $\mathrm{F}_{\mathrm{IO}_{2}}$ of 0.4 in air. It is reported that postoperative pulmonary complications can reach an incidence of $15-18 \% \%^{2,3}$ In particular, acute respiratory failure after lung surgery is fatal in up to $40 \%$ to more than $60 \% .^{2}$ In these circumstances, we conducted a prospective randomized controlled study with the aim to evaluate the effectiveness of the prophylactic application of CPAP delivered by hCPAP to improve oxygenation $\left(\mathrm{P}_{\mathrm{aO}_{2}} / \mathrm{F}_{\mathrm{IO}_{2}}\right)$, in comparison to oxygen therapy over an airentrainment mask $\left(\mathrm{F}_{\mathrm{IO}_{2}}\right.$ 0.4).

We found a significantly better $\mathrm{P}_{\mathrm{aO}_{2}} / \mathrm{F}_{\mathrm{IO}_{2}}$ after hCPAP, compared to the control group $(P=.001)$ after the second cycle of CPAP; however, this improvement was not long lasting and $\mathrm{P}_{\mathrm{aO}_{2}} / \mathrm{F}_{\mathrm{IO}_{2}}$ values were not significantly different in either group after 24 hours, 48 hours, and 1 week.

Additionally, postoperative complications were not statistically different in either groups. Finally, patients receiving postoperative hCPAP had a significantly shorter 
hospital stay, in comparison to the control group $(P=.042)$.

Dr Unnikrishnan and colleagues reported their indecision about the comparison of helmet interface over oxygen therapy via commonly used face mask. The authors' interest was to compare the standard institutional method of oxygen delivery after pulmonary lobectomy to a noninvasive method of ventilation, and not to compare 2 different ways (helmet and mask) of positive pressure oxygen supply. As described in the paper, the choice of the helmet interface was made by a definitely better acceptance, as compared to an oronasal mask. , $^{, 5}$

Comparing helmet interface versus facial interface, as proposed by Unnikrishnan et al, could certainly be the aim of a subsequent study.

Luca Ampollini MD Department of Thoracic Surgery

Maria Barbagallo MD Department of Anesthesia, Intensive Care, and Pain Therapy

University Hospital of Parma Parma, Italy

Stefanie Ziegler MD PhD Andrea Ortu MD

Department of Anesthesia and Intensive Care Umberto Parini Hospital Aosta, Italy

The authors have disclosed no conflicts of interest.

\section{REFERENCES}

1. Barbagallo M, Ortu A, Spadini E, Salvadori A, Ampollini L, Internullo E et al. Prophylactic use of helmet CPAP after pulmonary lobectomy: a prospective randomized controlled study. Respir Care 2012; 57(9):1418-1424.

2. Licker MJ, Widikker I, Robert J, Frey JG, Spiliopoulos A, Ellenberger C, et al. Operative mortality and respiratory complications after lung resection for cancer: impact of chronic obstructive pulmonary disease and time trends. Ann Thorac Surg 2006;81(5):1830-1837.

3. Dulu A, Pastores SM, Park B, Riedel E, Rusch V, Halpern NA. Prevalence and mortality of acute lung injury and ARDS after lung resection. Chest 2006;130(1):73-78.

4. Rocco M, Dell'Utri D, Morelli A, Spadetta G, Conti G, Antonelli M, Pietropaoli P. Noninvasive ventilation by helmet or face mask in immunocompromised patients: a case-control study. Chest 2004;126(5): 1508-1515.
5. Navalesi P, Costa R, Ceriana P, Carlucci A, Prinianakis GG, Antonelli M, et al. Non-invasive ventilation in chronic obstructive pulmonary disease patients: helmet versus facial mask. Intensive Care Med 2007;33(1):74-81.

DOI: $10.4187 /$ respcare. 02407

\section{Noninvasive Mechanical Ventilation and Helmet After Lung Resection: Oxygenation Improvement: A Small Step or a Large Step?}

\section{To the Editor:}

Noninvasive ventilation (NIV) may control the incidence of postoperative complications in selected patients who develop hypoxemia after some elective thoracic and abdominal surgery. As a prophylactic intervention, NIV may be important in patients at risk of hypoxemia after cardiac surgery or lobectomy.1,2 After lung surgery, early NIV may reduce pulmonary dysfunction and improve respiratory function. ${ }^{3}$

Barbagallo et $\mathrm{al}^{4}$ used helmet for prophylactic CPAP following lung resection and found short-term improved $\mathrm{P}_{\mathrm{aO}_{2}} / \mathrm{F}_{\mathrm{IO}_{2}}$ and shorter hospital stay, but no difference in complications. These results may improve our understanding of postoperative ventilatory support for preventing postoperative complications, but we see 5 important issues with their methods and results.

First, the extent of lung resection (lung lobectomy) means that the postoperative lung function in their patient population (which had a mean $\mathrm{FEV}_{1}$ of $>85 \%$ of predicted and a mean FVC of $>90 \%$ of predicted) was not substantially affected, and this may explain the high success rate in the Barbagallo et al study.

Second, the preoperative arterial blood gas exchange is a key to understanding their results, but $\mathrm{P}_{\mathrm{aO}_{2}} / \mathrm{F}_{\mathrm{IO}_{2}}$ immediately before initiating helmet CPAP (hCPAP) was not reported, so we can't determine the benefit obtained after the first hCPAP cycle. The study could not be blinded, but were any similar postoperative supportive measures used in the control group?

Third, it is not known whether prophylactic hCPAP resulted in overtreatment of some subjects.

Fourth, the relationship between improved oxygenation and hospital stay is un- known, and hCPAP only transiently improved oxygenation and did not significantly influence complications, so it is doubtful that hCPAP influenced stay. We would like to know the relationship between a shortterm improved oxygenation and the decision to discharge the patient earlier, which might have been influenced by physician bias, since the surgeon responsible for the discharge knew that the patient was given hCPAP.

Fifth, the relationship between the existence of minor complications in the hCPAP group versus the control group is interesting. Considering the absence of complications in the hCPAP group, the stay should have been compared to the stay of patients without major complications, and not to the stay of the control group, which had 4 patients with pneumonia and wound infection.

More studies are needed to determine hCPAP's effects on prognosis and postoperative complications. Also the presence of associated comorbidities at various postoperative periods needs to be studied. , $^{25-7} \mathrm{De}-$ spite these limitations and the necessity of randomized trials, we should consider helmet as a prophylactic and therapeutic tool to improve gas exchange in postoperative patients. ${ }^{2,8}$ We compliment them on their study.

Antonio M Esquinas MD PhD Intensive Care Unit

Hospital Morales Meseguer Murcia, Spain

Peter J Papadakos MD FAARC Department of Critical Care University of Rochester Rochester, New York

The authors have disclosed no conflicts of interest.

\section{REFERENCES}

1. Squadrone V, Coha M, Cerutti E, Schellino MM, Biolino P, Occella P, et al; Piedmont Intensive Care Units Network (PICUN). Continuous positive airway pressure for treatment of postoperative hypoxemia: a randomized controlled trial. JAMA 2005; 293(5):589-595.

2. Jaber S, Michelet P, Chanques G. Role of non-invasive ventilation (NIV) in the perioperative period. Best Pract Res Clin Anaesthesiol 2010;24(2):253-265.

3. Perrin C, Jullien V, Vénissac N, Berthier F, Padovani B, Guillot F, et al. Prophylactic use of noninvasive ventilation in patients 